\title{
Comparison between Force Deflection Values of Different Types of Orthod- \\ ontic Arch Wires.
}

Khudair A Al-Jumaili BDS, CES, D Sc (Proff)

Enas T Al-Jwary BDS, MSc (Assist Lect)

\author{
Dept of Pedod, orthod, and Prev Dentistry \\ College of Dentistry, University of Mosul
}

\section{ABSTRACT}

Aims: To evaluate the force values of different types of arch wires. Materials and Methods: Five types of arch wires used. The sample consisted of 150 wires specimens divided into three deflections (1 $\mathrm{mm}, 2 \mathrm{~mm}$ and $3 \mathrm{~mm}$ ). A universal tensile testing machine with the use of special designed fixture was used to perform Three Point Bending Test and the force value related to gram (gm) was measured during loading (activation) of the wire to $1 \mathrm{~mm}, 2 \mathrm{~mm}$ or $3 \mathrm{~mm}$ deflections. Results: The results of this investigation showed a significant difference $(P \leq 0.05)$ in force values among all arch wires. Conclusions: The conclusions of this study showed that the solid stainless steel wires provided a heavy force, while the multistranded gave rise to the lowest force value.

Key words : Force values, Orthodontic Arch Wires.

Al-Jumaili KA, Al-Jwary ET.Comparison between Force Deflection Values of Different Types of Orthodontic Arch Wires. Al-Rafidain Dent J. 2007; 7(SpIss): 58S-63S.

Received: 15/10/2006 Sent to Referees: 16/10/2006

Accepted for Publication: 11/1/2007

\section{INTRODUCTION}

A vital component of the fixed orthodontic appliance is the orthodontic arch wire $^{(1)}$. Orthodontic arch wires through their engagement with the brackets generated biomechanical forces necessary to move the teeth. Orthodontists are constantly searching for the most effective arch wire $^{(2)}$. The first stage of orthodontic treatment entails leveling and aligning the teeth. To accomplish this, an appliance that delivers forces that are light and decrease only moderately between appointments is required ${ }^{(3)}$. It would be a clinical advantage if an arch wire could produce this light and constant delivery of force over a period of weeks such forces may reduce the potential for tissue hyalinization, undermining resoption and periodontal ligament necrosis ${ }^{(4)}$. For the patient's benefit, the ideal wire should allow a rapid tooth movement with a minimum of discomfort ${ }^{(5)}$. So, the choice of most suitable orthodontic wire for each stage of treatment requires an estimation of the forces generated (6). Several researchers have considered that the choice should be based on the estimations of forces produced by different arch wires and on a comparison of the obtained values with the optimal force that produces the most effective tooth movement ${ }^{(7-10)}$.

These wire forces depend on the wire deformation (such as on the tooth deviations from the right positions and inter tooth distance) and on a wire cross section and material ${ }^{(11,12)}$. Also, the behavior and performance of wires can be affected by corrosion in the mouth ${ }^{(13)}$.

Recent advances in orthodontic wire alloys have resulted in a varied array of wires and these include stainless steel, cobalt-chromium, nickel-titanium, betatitanium and multistranded stainless steel wires ${ }^{(14)}$. Each alloy system and subdivision have unique properties and characteristics ${ }^{(4)}$. So, knowledge of force deflection behavior of each wire is important to the clinician for optimal wire selection ${ }^{(15)}$. The aims of the study are to evaluate the force values of different types of orthodontic arch wires and to compare the force values among these wires.

\section{MATERIALS AND METHODS}

Five types of orthodontic wires were taken which included extra spring hard SS wire, spring hard SS wire, multistranded SS wire, nitinol and super elastic NiTi wires (Dentaurum, Germany). The 0.016 
inch wires were selected except multistranded ( 0.015 inch); because popularity of 0.016 inch wire with the clinicians for initial leveling and aligning, because these are the most likely wires to be recycled ${ }^{(16)}$. The specimens' length of the arch wires used in this study was $50 \mathrm{~mm}{ }^{(17)}$. For the preformed arch wire; the most straight posterior segments were cut for testing.

The extra spring hard SS wire showed a permanent deformation and bending of the wires at $4 \mathrm{~mm}$ deflection in this study, so only $1 \mathrm{~mm}, 2 \mathrm{~mm}$ and $3 \mathrm{~mm}$ deflections were taken in this study for the comparison between wires. The measurement of force deflection behavior of arch wires done with a unive-rsal tensile testing machine (Festigkeits - Prufmaschine F 410, Germany), Figure (1) with a full scale range of $2000 \mathrm{gm}$ in a $5 \mathrm{gm}$ graduation.

The load deflection characteristics of specimens were evaluated with the help of three point bending test as described by many authors ${ }^{(17-20)}$.

Three Point Bending Test was performed on the especially designed fixture which prepared according to the design described by previous studies ${ }^{(18,21)}$. This fixture, Figure (2) was consists of the following parts:

1. A metal stage of about $(3.5 \times 15)$ $\mathrm{cm}$ in diameter was used in which two steel poles of about $5 \mathrm{~mm}$ in diameter were fixed, these two poles placed $14 \mathrm{~mm}$ a part on this stage. A standard edgewise stainless steel bracket $(0.018 \times 0.030)$ inch (Dentaurum, Germany); fixed on each pole by using epoxy steel resin (Eaglestar,

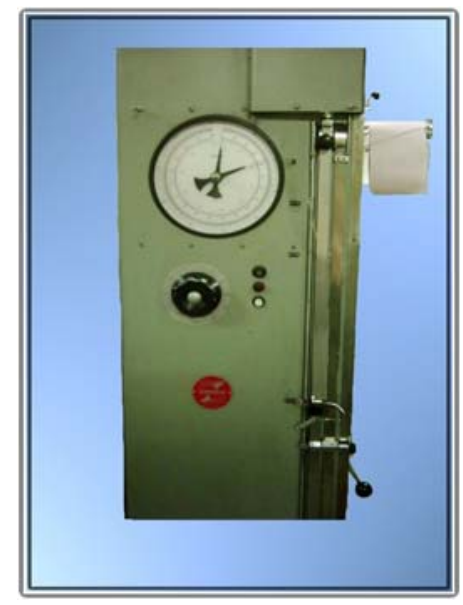

Figure 1: Universal Tensile Testing Machine
USA). This metal stage attached to a fixed head of universal tensile testing machine and this attached to load cell.

2. A second metal stage was used in which a metal arm of about $(7 \mathrm{~cm})$ in length was extended. At the end of this arm, a single steel pole $(5 \mathrm{~mm})$ in diameter was fixed and this stage attached to a movable arm of a universal.

The wire specimen was attached to the brackets on the two poles by ligature elastics (Orthomatrix, USA).The stage of single pole was attached to a movable head of a universal tensile testing machine, so that the single pole was on the center of the wire span.

The mid portion of the wire was then deflected by the pressure of the single pole with a cross head speed of $0.5 \mathrm{~mm} / \mathrm{sec}$ and the load value was measured at each deflection distance. So, ten wires of each type were measured during loading (activation) of wires to $1 \mathrm{~mm}$ deflection and the same procedure repeated to measure force values at $2 \mathrm{~mm}$ and $3 \mathrm{~mm}$ deflections. All the tests were performed at room temperature at $30 \pm 0.5^{\circ} \mathrm{C}$. The statistical analysis used in this study includes descriptive statistics to show mean, standard deviation and standard error for each. The Analysis of variance (ANOVA)-one way, was used to assess the significant difference among the groups at $P \leq 0.01$ significant level; and Duncan's Multiple Range Test was performed to located the significant differences among the groups at $P \leq 0.05$ significant level.

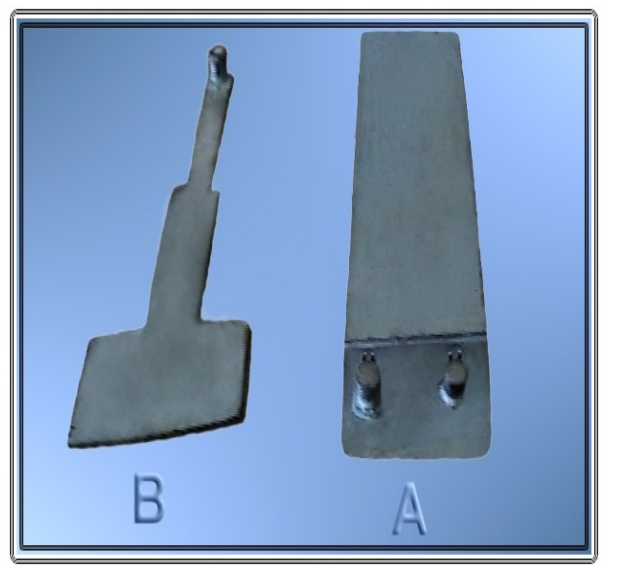

Figure 2: Special Design Fixture. 


\section{RESULTS}

The analysis of variance (ANOVA) and the Duncan's Multiple Range Test of force rate (gm) at $1 \mathrm{~mm}, 2 \mathrm{~mm}$ and $3 \mathrm{~mm}$ deflection during loading were listed in Tables (1, 2, 3, 4, 5 and 6).

The findings of the study showed that the extra spring hard stainless steel wire gave rise to the highest rate of force with a significant difference $P \leq 0.05$, than other types of wires in all deflection distances.

\section{DISCUSSION}

The activation of the wire to 1,2 and $3 \mathrm{~mm}$ deflections showed that the extra spring hard SS wires had signi-ficantly higher mean of force values than other types of wires and this finding rel-ates to the mechanical properties of stai-nless steel wires which have higher stiff-ness (elastic modulus) and it coincides with others studies ${ }^{(2,18,21)}$, who attributed these findings to the greater stiffness (elas-tic modulus) of SS wire as compared with other types of wires.

On the other hand, the multistranded SS wires displayed the lowest mean value of force with significant differences from the other types of wires and this is due to the higher flexibility of multistranded SS and this is in agreement with others studies $^{(17,22,23)}$, who related these findings to the lower load deflection rate, higher flexibility and low stiffness of multistranded SS wires.

The force values of spring hard SS wire was significantly higher than the other types of wires and lower than the extra spring hard SS wire, such finding is in agreement with others studies ${ }^{(24,25,26)}$, who related this finding to the difference in the hardness, the spring hard SS wire has a low hardness than extra spring hard SS wire .

The nitinol wire gave rise to force value with significant greater difference than the other types of wires and less than that of SS wires and this finding attributes to elastic modulus (stiffness) of nitinol and it corresponds to the findings obtained by others studies ${ }^{(18,20)}$. This result was supported by Johnson and Lee ${ }^{(27)}$, who disclosed that the relative stiffness of nitinol is less than that of solid SS wire and higher than that of the triple flex SS wire. Also, this finding is similar to the result reported by Goldberg et al. ${ }^{(28)}$, who showed that for any deflection, the force applied by nitinol wire was less than that applied by SS wire of the same dimension.

Table (1): ANOVA for Demonstrated Force Value (gm) of Different Orthodontic Wires Types during Loading Force at $1 \mathrm{~mm}$ Deflection.

\begin{tabular}{cccccc}
\hline Source of variance & Sum of Square & df & Mean Square & F-value & $\boldsymbol{P}$-value \\
\hline Between groups & 1042337.0 & 4 & 260584.250 & & \\
Within groups & 147.5 & 45 & 3.278 & 79500.280 & $\mathrm{P}<0.001$ \\
Total & 1042484.5 & 49 & & & \\
\hline
\end{tabular}

Df: Degree of freedom.

Table (2): Duncan's Multiple Range Test for Demonstrated Force Value related to grams (gm) of Different Orthodontic Wires Types during Loading Force at $1 \mathrm{~mm}$ Deflection.

\begin{tabular}{cccc}
\hline Types of Wires & \multicolumn{2}{c}{ Number Mean \pm SE (Force in gm) } & $\begin{array}{c}\text { Duncan } \\
\text { Groups* }\end{array}$ \\
\hline Extra spring hard stainless steel & 10 & $531.000 \pm 0.666$ & $\mathbf{A}$ \\
Spring hard stainless steel & 10 & $490.500 \pm 0.500$ & B \\
Multistranded stainless steel & 10 & $154.500 \pm 0.500$ & E \\
Nitinol & 10 & $244.000 \pm 0.666$ & D \\
Super elastic nickel- titanium & 10 & $300.500 \pm 0.500$ & C \\
\hline
\end{tabular}

* Different litters mean significant difference $(P \leq 0.05)$. 
Table (3): ANOVA for Demonstrated Force Value (gm) of Different Orthodontic Wires Types during Loading Force at $2 \mathrm{~mm}$ Deflection.

\begin{tabular}{ccccccc}
\hline Source of variance & Sum of Square & df & Mean Square & F-value & $P$-value \\
\hline Between groups & 1691877.0 & 4 & 422969.250 & & \\
Within groups & 107.5 & 45 & 2.389 & 177056.90 & $P \leq 0.001$ \\
Total & 1691984.5 & 49 & & & \\
\hline
\end{tabular}

Df: Degree of freedom.

Table (4): Duncan's Multiple Range Test for Demonstrated Force Value related to grams (gm) of Different Orthodontic Wires Types During Loading Force at $2 \mathrm{~mm}$ Deflection.

\begin{tabular}{cccc}
\hline Types of Wires & Number & Mean \pm SE (Force in gm) & $\begin{array}{c}\text { Duncan } \\
\text { Groups* }\end{array}$ \\
\hline Extra spring hard stainless steel & 10 & $690.000 \pm 0.000$ & $\mathbf{a}$ \\
Spring hard stainless steel & 10 & $679.500 \pm 0.500$ & b \\
Multistranded stainless steel & 10 & $240.500 \pm 0.500$ & e \\
Nitinol & 10 & $360.500 \pm 0.500$ & c \\
Super elastic nickel- titanium & 10 & $359.000 \pm 0.666$ & d \\
\hline
\end{tabular}

* Different litters mean significant difference $(P \leq 0.05)$.

Table (5): ANOVA for Demonstrated Force Value (gm) of Different Orthodontic Wires Types During Loading Force at (3) mm Deflection.

\begin{tabular}{cccccc}
\hline Source of variance & Sum of Square & df & Mean Square & F-value & $P$-value \\
\hline Between groups & 2810140.0 & 4 & 702535.000 & & \\
Within groups & 160.0 & 45 & 3.556 & 197587.97 & $P \leq 0.001$ \\
Total & 28103000.0 & 49 & & & \\
\hline
\end{tabular}

Df: Degree of freedom.

Table (6): Duncan's Multiple Range Test for Demonstrated Force Value related to grams (gm) of Different Orthodontic Wires Types During Loading Force at (3) mm Deflection.

\begin{tabular}{cccc}
\hline Types of Wires & Number & Mean \pm SE (Force in gm) & $\begin{array}{c}\text { Duncan } \\
\text { Groups* }\end{array}$ \\
\hline Extra spring hard stainless steel & 10 & $849.000 \pm 0.666$ & a \\
Spring hard stainless steel & 10 & $850.000 \pm 0.000$ & a \\
Multistranded stainless steel & 10 & $296.000 \pm 0.666$ & d \\
Nitinol & 10 & $424.000 \pm 0.666$ & b \\
Super elastic nickel- titanium & 10 & $401.000 \pm 0.666$ & c \\
\hline
\end{tabular}

* Different litters mean significant difference $(\mathrm{P} \leq 0.05)$; SE: Standard error.

The super elastic (nickel - titanium) wire gave rise to the significant higher force values than the multistranded SS wires and less than that of extra spring hard SS wire and spring hard SS wire wires. This result relates to the flexibility of super elastic wire and such finding coincides with Chen et al. ${ }^{(29)}$, who cited that the Chinese NiTi wire possessed unique low stiffness and it offered a nearly con- 
stant force which was desirable in orthodontic application. This result was in agreement with Burstone et al. ${ }^{(30)}$, who concluded that the Chinese NiTi wire was highly suitable if low force was required and large deflection was needed.

The result of the present study showed that the super elastic wire at $1 \mathrm{~mm}$ deflection displayed a significant higher force value than the nitinol wire. This relates to the phase transformation of this alloy from austenitic to martensitic phase (which was a low stiffness phase) does not occur at small deflection, in other words, stress induced martensitic transformation (SIM) does not occur, so the wire act as conventional wire. This finding corresponds with other authors ${ }^{(18,30,31)}$. Also this finding was similar to the finding of Segner and Ibe ${ }^{(32)}$, who concluded that the super elastic plateau only occurred at deflection greater than $1.5 \mathrm{~mm}$.

Furthermore, at $2 \mathrm{~mm}$ and $3 \mathrm{~mm}$ deflections, the super elastic wire gave rise to a force value which was significantly lower than the nitinol wire and this attributes to stress induced martensitic transformation (SIM) which converts it to martensitic phase and gave rise to super elastic properties of the wire, so displayed low force than conventional NiTi wire and this finding was in agreement with others authors $(18,29,30)$

\section{CONCLUSIONS}

When comparing the load deflection of different types of wires, the extra spring hard SS wires provided a significant higher force values, while the multistranded SS wires provided a significant lighter load values. On the other hand, the remaining types of wires distributed on statistical levels of a significant differences $(P \leq$ 0.05 ) between the upper and lower levels of force values.

\section{REFERENCES}

1.Gurgel J, Kerr S, Powers J, Lecrone V .Force deflection properties of superelastic nickel - titanium archwires. Am J Orthod Dentofac Orthop. 2001; 120(4): 378-382.

15.Nikolai R. Flexural activation and deactivation responses of orthodontic wires in single tooth occlusogingival corrections. Dent Mater. 1989; 5(5): 339-345.
2.Proffit W. Contemporary Orthodontics. $3^{\text {rd }}$ ed., Mosby Company, ST. Louis .2000; Pp 328-329, 526-527.

3.Evans T, Jones M, Newcombe RG. Clinical comparison and performance perspective of three aligning arch wires. Am J Orthod Dentofac Orthop. 1998; 114(1): 32-39.

4.Kusy P. A review of contemporary arch wires: Their properties and characteristics. Angle Orthod. 1997; 67(3): 197-207.

5.Julio de A, Stephen K, John M, Arnaldo P. Torsional properties of commercial nickel titanium wires during activation and deactivation. Am J Orthod Dentofac Or-thop. 2001; 120(1): 76-79.

6.Garrec P, Tavernier B, Jordan L. Evolution of flexural rigidity according to the cross sectional dimension of a super elastic nickel - titanium orthodontic wire. Eur J Orthod. 2005; 27(4): 402-407.

7.Quin R, Yoshikawa D. A reassessment of force magnitude in orthodontics. Am J Orthod. 1985; 88(3): 252-260.

8.Klump J, Duncanson M, Nanda R. Elastic energy / stiffness ratio for selected orthodontic wires. Am J Orthod Dentofac Orthop. 1994; 106(6): 588-596.

9.Meling T, Degaard J, Holthe K, Odegaard E, Segner D. A formula for the displacement of an arch wire when subjected to a second order couple. Am J Orthod Dentofac Orthop. 1998; 113(6): 632-640.

10.Muraviev S, Ospanova G, Shliakhiva M. Estimation of force produced by nickel titanium super elastic arch wires at large deflections. Am J Orthod Dentofac Orthop. 2001; 119(6): 604-609.

11.Burstone C. Variable- modulus orthodontics. Am J Orthod. 1981; 80(1): 1-16.

12.Halazonetis D. Ideal arch force systems: A center-of-resistance perspective. Am J Orthod Dentofac Orthop. 1998; 114(3): 256264.

13.Thompson S. An overview of nickel titanium alloys used in dentistry. Int Endod J. 2000; 33(4): 297-310.

14.Kapila S, Sachdeva R. Mechanical properties and clinical application of orthodontic wires. Am J Orthod Dentofac Orthop. 1989; 96(2): 100-109.

16.Smith G, Fraunhofer J, Casey G. The effect of clinical use and sterilization on selected orthodontic arch wires. Am J Orthod Dentofac Orthop. 1992; 102(2): 153-159. 
17.Taneja P, Duncanson M, Khajotia S, Nanda R. Deactivation force deflection behavior of multistranded stainless steel wires. Am $J$ Orthod Dentofac Orthop. 1992; 124(1): 6168.

18.Miura F, Mogi M, Ohura Y, Hamanaka H. The superelastic property of the Japanese $\mathrm{NiTi}$ alloy wire for use in orthodontics. $\mathrm{Am}$ J Orthod. 1986; 90(1): 1-10.

19.Kapila S, Reichhold G, Anderson R, Watanabe L. Effects of clinical recycling on mechanical properties of nickel-titanium alloy wires. Am J Orthod Dentofac Orthop. 1991; 100(5): 428-435.

20.Jay M, Manville G, Joy D, Nanda R. Stiffness-deflection behaviour of selected orthodontic wires. Angle Orthod. 1997; 67(3): 209-218.

21.Krishnan V, Kumar K. Mechanical properties and surface characteristics of three arch wire alloys. Angle Orthod. 2004; 74(6): 823-829.

22.Bantleon H, Droschi H, Pfeiffer K. New wires and their force delivery-consequences for orthodontic therapy. Fortschr Kieferorthop. 1989; 50(4): 243-255. (Abstract )

23.Wilkinson P, Dysart P, Hood J, Herbison G. Load deflection characteristics of super elastic nickel titanium orthodontic wires. Am J Orthod Dentofac Orthop. 2002; 121(5): 483-495.
24.Combe E. Notes of Dental Materials. $5^{\text {th }}$ ed., Churchill LivingStone. 1986; Pp: 58, $68,73$.

25.Noort R. Introduction to Dental Materials. $2^{\text {nd }}$ ed., Mosby Company. 2002; Pp: 25, $27-$ 28,42 .

26.Ireland A, McDonald F. The Orthodontic Patient: Treatment and Biomechanics, Oxford University Press. 2003; Pp: 210, 211, $215,217$.

27.Johnson E, Lee RS. Relative stiffness of orthodontic wire. J Clin Orthod. 1989; 23(5): 353-363.

28.Goldberg A, Burstone C, Koenig A. Plastic deformation of orthodontic wires. J Den Res. 1983; 62(9): 1016-1020.

29.Chen R, Zhi Y, Arvystas M :Advanced Chinese NiTi alloy wire and clinical observation. Angle Orthod. 1992; 62 (1): 59-66.

30.Burstone C, Qin B, Morton J. Chinese NiTi wire: A new orthodontic alloy. Am J Orthod. 1985; 87(6): 445-452.

31.Garrec P, Jordan L. Stiffness in bending of a super elastic NiTi orthodontic wire as a function of cross sectional dimension. Angle Orthod. 2004; 74(5): 691-696.

Segner D, Ibe D. Properties of super elastic wires and their relevance to orthodontic treatment. Eur J Orthod. 1995; 17(5): 395-402. 